\title{
Helicobacter pylori among symptomatic Egyptian children: prevalence, risk factors, and effect on growth
}

\author{
Yasmine Samir Galal ${ }^{1 *}$ D, Carolyne Morcos Ghobrial ${ }^{2}$, John Rene Labib ${ }^{3}$ and Maha Elsayed Abou-Zekri ${ }^{4}$
}

\begin{abstract}
Aim: This study was carried out to determine the prevalence and predictors of Helicobacter pylori (H. pylori) infection among symptomatic children and the effect on growth.

Methods: A cross-sectional study was conducted in the Outpatient Clinics of the Gastroenterology Unit of the Pediatric Hospital, Cairo University. A total of 630 children complaining of any symptoms or signs suspicious of $H$. pylori infection were enrolled. Weight and height were measured for each child, and the standard deviation scores (Z-scores) for weightfor-age (WAZ), weight-for-height (WHZ), and height-for-age (HAZ) were calculated. H. pylori was diagnosed using a stool antigen test.

Results: The overall prevalence of infection was $64.6 \%$. Socio-demographic variables significantly associated with $\mathrm{H}$. pylori were residence in Upper Egypt $(P=0.013)$ and rural areas $(P=0.004)$, illiteracy of mothers $(P=0.017)$, household crowding index $\geq 3(P=0.011)$, absence of pure water supply $(P=0.005)$, and eating from street vendors $(P<0.001)$. Values of WAZ [median, interquartile range (IQR) in infected $=-1.3(-2.7$ to -0.4$)$ and non-infected $=-0.7(-2.1$ to -0.1$), P<0.001], H A Z$ $(P=0.036)$, and $\mathrm{WHZ}(P=0.005)$ were significantly lower in children infected with $H$. pylori. After performing a backward logistic regression analysis, eating from street vendors ( $\mathrm{OR}=1.879,95 \% \mathrm{Cl} 1.346-2.625, P<0.001)$, absence of pure water supply $(\mathrm{OR}=1.725,95 \% \mathrm{Cl} 1.162-2.561, P=0.007)$, and overcrowding $(\mathrm{OR}=1.547,95 \% \mathrm{Cl} 1.100-2.177, P=0.012)$ remained the significant predictors of $H$. pylori infection.

Conclusion: A high prevalence of $H$. pylori infection among symptomatic children was detected. The extra-digestive effects of $\mathrm{H}$. pylori were revealed in the form of affection of growth parameters and reduced levels of serum hemoglobin, iron, and ferritin.
\end{abstract}

Keywords: Helicobacter pylori, Prevalence, Growth parameters, Malabsorption, Iron-deficiency anemia

\section{Introduction}

Helicobacter pylori (H. pylori) is one of the most common chronic infections with a worldwide prevalence of about $50 \%$ [1]. This infection is predominantly acquired during early childhood especially in poor countries $[2,3]$. The prevalence of $H$. pylori varies markedly between countries [4]; about $50 \%$ of children are infected by 10 years of age in developing countries [5].

The mode of transmission of $H$. pylori through the fecal-oral or oral-oral routes [6] was supported by the

\footnotetext{
* Correspondence: yasmine.galal@hotmail.com

${ }^{1}$ Departments of Public Health and Community Medicine, Faculty of

Medicine, Cairo University, 31 Mohamed Hassan El-Gamal Street, Nasr City,

Cairo 11759, Egypt

Full list of author information is available at the end of the article
}

evidence that most risk factors for infection are closely related to poor living conditions including lower socioeconomic status, bad hygiene, deficiency of sanitation, household crowding, bed sharing, and food- and waterborne transmission [7-9].

H. pylori has been recognized as a causative agent of chronic gastritis [10, 11]. However, extra-digestive effects on growth parameters have been reported in young children. A wide range of studies has stated an association between $H$. pylori infection and childhood growth impairment [12-14]. One mechanism is that $H$. pylori causes depressed gastric acid secretion, which could result in infection with enteropathogens leading to diarrhea, malabsorption of nutrients, reduced food intake as a result of 
dyspepsia, and iron-deficiency anemia (IDA) [15, 16]. However, proving the role of $H$. pylori alone in childhood growth impairment is difficult where numerous confounding variables such as socio-economic status and diet also exist [17].

Despite that $H$. pylori infection constitutes a public health problem often with serious complications especially in a developing country like Egypt, few studies were conducted revealing high rates of infection in both adults $[18,19]$ and the pediatric age groups $[20,21]$.

Since evidence from the literature postulates that $H . p y l-$ ori infection occurs mostly during childhood [2], studying the epidemiology of this infection in pediatric patients can enable better understanding of the risk factors and consequences of infection. Therefore, this study was conducted in the Pediatric Hospital of Cairo University to determine the prevalence of $H$. pylori infection among children, to identify the different predictors that may influence the acquisition of infection and the effect on growth.

\section{Material and methods}

\subsection{Study design, period, and setting}

This was a cross-sectional, hospital-based study conducted in the Outpatient Clinics of the Gastroenterology Unit of the Pediatric Hospital, Cairo University. The study took place over a 6-month period from February till July 2017. About 500-600 patients per month attend the outpatient clinic with different gastrointestinal problems.

\subsection{Study population}

All patients attending the Outpatient Clinics of the Gastroenterology Unit during the study period and complaining of any symptoms or signs suspicious for $H$. pylori infection (abdominal pain, anemia not responding to treatment, recurrent vomiting, and upper gastrointestinal bleeding) were recruited. A total of 630 children $\leq 18$ years were enrolled for the study. Children with history of previous use of antibiotics or proton-pump inhibitors at least 2 weeks before attending the outpatient clinics were excluded.

\subsection{Study tools and data collection}

\subsubsection{Demographic details and clinical features}

a) A pre-test structured questionnaire was used to collect information from the children's parents regarding possible risk factors for infection including the following: (i) socio-demographic characteristics including age, gender, residence, mother education (non-educated were illiterates and educated were those who completed any stage of education), household crowding index (number of people living in the household/number of rooms), and availability of potable water; and (ii) dietary practices, such as daily eating from street vendors.

Household crowding index: the house was considered crowded when the number of persons living in the house divided by the number of rooms was $\geq 3$.

Questions used in this section were adopted from the available literature $[6,20]$ by the researchers and were revised by three experts from Public Health and Pediatrics to check content validity. Pilot testing: the preliminary data collection form was tested on 20 cases to assess the clarity and comprehension of questions and the time needed to answer the questionnaire.

b) Patients' records were reviewed for the following: (i) presenting symptoms and signs (abdominal pain, vomiting, hematemesis, melena, and pallor) and (ii) history of medications-proton pump inhibitors and antibiotics.

\subsection{Anthropometric measurements}

Weights were measured using electronic scales, and heights were measured using length boards. For children over 2 years, height sticks were used. Then, the standard deviation scores (Z-scores) for weight-for-age (WAZ), weight-forheight (WHZ), and height-for-age (HAZ) were calculated using the Center of Disease Control (CDC) online calculator program. [22]

\subsection{Laboratory tests}

Blood samples were collected from each child and sent to the Clinical and Chemical Pathology Department at the Faculty of Medicine, Cairo University, to measure serum hemoglobin, serum iron and ferritin, liver function tests [alanine transaminase (ALT), aspartate transaminase (AST), total bilirubin, and albumin], and coagulation profile [prothrombin time (PT), prothrombin concentration (PC), and international normalized ratio (INR)].

\subsection{Helicobacter pylori testing}

H. pylori was diagnosed using a stool antigen test which is rapid, non-invasive, reliable, easy to perform and can be used to detect an existing infection. Participants were given clean, leak proof containers to provide fresh stools within 2 $\mathrm{h}$; the children and/or their parents were asked to identify the time and date of specimen collection. All stool specimens were collected and transported in a cold $\left(-4{ }^{\circ} \mathrm{C}\right)$ specimen carrier to the laboratory. Specimens that were expected to stay more than $2 \mathrm{~h}$ before processing were frozen at $\left(-20^{\circ} \mathrm{C}\right)$. A lateral flow immunochromatographic assay for detection of $H$. pylori antigen in stool was used with a sensitivity of $96 \%$ and specificity of $83 \%$. [23] Based on the intensity of the color developed, results were reported as $H$. 
pylori antigen not detected, equivocal, or detected [Onsite H. pylori Rapid Ag test].

\subsection{Statistical analysis}

Pre-coded data was entered on the computer using the Statistical Package of Social Science Software Program (SPSS), version 23 , to be statistically analyzed. Data was presented using mean, median, range, and interquartile range for quantitative variables and frequency and percentages for qualitative ones. Comparison between groups was performed using Mann Whitney test for quantitative variables and chi-square test for qualitative ones. Backward stepwise logistic regression model was conducted to explore the predictors of $H$. pylori infection. $P$ values less than 0.05 were considered statistically significant.

\section{Results}

Table 1 shows the socio-demographic data, dietary practices, and predictive clinical features among the studied population. A total of 630 children, 325 males (51.6\%) and 305 females (48.4\%), were enrolled for the study. The total number of $H$. pylori-positive individuals was 407 (64.6\%). The participants' age ranged from 1 to 15 years with a median of 7 years. The highest prevalence of $H$. pylori infection was among children $>10$ years $(32.9 \%)$, while the lowest was among those $<3$ years (13.8\%), with no

Table 1 Association of $H$. pylori infection among symptomatic Egyptian children with sociodemographic, personal, and clinical data

\begin{tabular}{|c|c|c|c|c|c|c|}
\hline & \multicolumn{2}{|c|}{ Stool antigen for $\mathrm{H}$. pylori } & \multirow[t]{2}{*}{ Total } & \multirow[t]{2}{*}{$p$ value } & \multirow[t]{2}{*}{ OR } & \multirow[t]{2}{*}{$95 \% \mathrm{Cl}$} \\
\hline & $\begin{array}{l}+\mathrm{VE} \\
(n=407)\end{array}$ & $\begin{array}{l}-V E \\
(n=223)\end{array}$ & & & & \\
\hline \multicolumn{7}{|l|}{ Age groups } \\
\hline$<3$ years & $56(13.8 \%)$ & $33(14.8 \%)$ & 89 & Ref & Ref & Ref \\
\hline $3-6$ years & $102(25.1 \%)$ & $72(32.3 \%)$ & 174 & 0.500 & 0.835 & $0.494-1.412$ \\
\hline $7-10$ years & $115(28.3 \%)$ & $43(19.3 \%)$ & 158 & 0.107 & 1.576 & $0.905-2.745$ \\
\hline$>10$ years & $134(32.9 \%)$ & 75 (33.6\%) & 209 & 0.845 & 1.053 & $0.629-1.762$ \\
\hline \multicolumn{7}{|l|}{ Sex } \\
\hline Male & $205(50.4 \%)$ & $120(53.8 \%)$ & 325 & 0.408 & 0.871 & $0.628-1.208$ \\
\hline Female & $202(49.6 \%)$ & $103(46.2 \%)$ & 305 & Ref & Ref & Ref \\
\hline \multicolumn{7}{|l|}{ Region } \\
\hline Upper Egypt & $186(45.7 \%)$ & 79 (35.4\%) & 265 & 0.013 & 1.534 & $1.096-2.148$ \\
\hline Lower Egypt & $221(54.3 \%)$ & $144(64.6 \%)$ & 365 & Ref & Ref & Ref \\
\hline \multicolumn{7}{|l|}{ Residence } \\
\hline Urban & $161(39.6 \%)$ & $115(51.6 \%)$ & 276 & 0.004 & 0.615 & $0.442-0.854$ \\
\hline Rural & $246(60.4 \%)$ & $108(48.4 \%)$ & 354 & Ref & Ref & Ref \\
\hline \multicolumn{7}{|l|}{ Mother education } \\
\hline Educated & $157(38.6 \%)$ & $108(48.4 \%)$ & 265 & 0.017 & 0.669 & $0.481-0.930$ \\
\hline Not educated & $250(61.4 \%)$ & $115(51.6 \%)$ & 365 & Ref & Ref & Ref \\
\hline \multicolumn{7}{|l|}{ Crowding index } \\
\hline$\geq 3$ & $270(66.3 \%)$ & $125(56.1 \%)$ & 395 & 0.011 & 1.545 & $1.105-2.160$ \\
\hline$<3$ & $137(33.7 \%)$ & 98 (43.9\%) & 235 & Ref & Ref & Ref \\
\hline Pure water supply & $283(69.5 \%)$ & $178(79.8 \%)$ & 461 & 0.005 & 0.577 & $0.391-0.852$ \\
\hline Eating from street vendors & $246(60.4 \%)$ & 99 (44.4\%) & 345 & $<0.001$ & 1.914 & $1.375-2.663$ \\
\hline \multicolumn{7}{|l|}{ Symptoms and signs } \\
\hline Abdominal pain & $310(76.2 \%)$ & $142(63.7 \%)$ & 452 & 0.001 & 1.823 & $1.277-2.602$ \\
\hline Vomiting & $24(5.9 \%)$ & $0(0 \%)$ & 24 & $<0.001$ & NA & NA \\
\hline Hematemesis & $378(92.9 \%)$ & $177(79.4 \%)$ & 555 & $<0.001$ & 3.387 & $2.059-5.573$ \\
\hline Melena & $182(44.7 \%)$ & 99 (44.4\%) & 281 & 0.938 & 1.013 & $0.729-1.407$ \\
\hline Pallor & 39 (9.6\%) & $7(3.1 \%)$ & 46 & 0.003 & 3.270 & $1.438-7.439$ \\
\hline
\end{tabular}

$+V E$ positive, $-V E$ negative, Ref reference, $O R$ odds ratio, $C l$ confidence interval, NA not applicable

${ }^{\#}$ Chi square test 
statistical differences. Apart from age and sex, the following socio-demographic variables were significantly less associated with $H$. pylori infection: residence in urban areas $(\mathrm{OR}=0.615,95 \%$ CI $0.442-0.854, P=0.004)$, literacy of mothers $(\mathrm{OR}=0.669,95 \%$ CI $0.481-0.930, P=0.017)$, crowding index $\geq 3(\mathrm{OR}=1.545,95 \% \mathrm{CI} 1.105-2.160, P=$ $0.011)$, and presence of pure water supply $(\mathrm{OR}=0.577$, $95 \%$ CI $0.391-0.852, P=0.005)$. Eating from street vendors was significantly associated with positive $H$. pylori infection $(\mathrm{OR}=1.914,95 \%$ CI 1.375-2.663, $P<0.001)$.

Clinical symptoms and signs significantly associated with positive $H$. pylori infection included abdominal pain $(\mathrm{OR}=$ 1.823, 95\% CI 1.277-2.602, $P=0.001)$, vomiting $(P<0.001)$, hematemesis $(\mathrm{OR}=3.387,95 \% \mathrm{CI} 2.059-5.573, P<0.001)$, and pallor $(\mathrm{OR}=3.270,95 \% \mathrm{CI} 1.438-7.439, P=0.003)$ (Table 1).

The values of WAZ [median (IQR) in infected =$1.3(-2.7$ to -0.4$)$ and non-infected $=-0.7(-2.1$ to $0.1), P<0.001]$, HAZ [median (IQR) in infected $=-$ $1.3(-2.2$ to 0.1$)$ and non-infected $=-0.9(-2.0$ to 0.1$), P$ $=0.036]$, and WHZ [median (IQR) in infected $=-1.2(-$ 2.9-0.3) and non-infected $=-0.3(-2.1-0.5), P=0.005$ ] were significantly lower in children (whole sample) infected with $H$. pylori infection compared with children free of infection (Table 2).

Figure $1 \mathrm{a}, \mathrm{b}, \mathrm{c}$ illustrates the anthropometric measurements (WAZ, HAZ, and WHZ) in relation to infection status and sex. These values did not show significant decline within $H$. pylori-infected males when compared to non-infected ones. However, H. pylori-infected females showed significant decline in both WAZ (median $(\mathrm{IQR})$ : infected $=-$ $1.4(-2.8$ to -0.2$)$ and non-infected $=-0.5(-2.1$ to 0.1$) ; P$ $=0.003)$ and WHZ (median (IQR): infected $=-1.5(-3.6$ to $-0.5)$ and non-infected $=-0.3(-2.6$ to 0.2$) ; P=0.006)$ but not in HAZ (median (IQR): infected $=-0.9(-2.0$ to 0.4 ) and non-infected $=-0.4(-1.2-0.2) ; P=0.097)$.

Regarding laboratory investigations, levels of serum hemoglobin (median, interquartile range (IQR): infected $=$ $10.6(9.4-11.2)$ and non-infected $=11.0(10.1-13.0) ; P<$ 0.001), ferritin (median (IQR): infected $=17.5(9.0-60.0)$ and non-infected $=41.0(15.1-60.0) ; P<0.001)$, and iron (median (IQR): infected $=41.0(25.0-71.0)$ and non-infected $=46.0(34.0-70.0) ; P=0.015)$ were significantly reduced in infected children. No significant association was found between infected and non-infected children as regards INR, liver enzymes, and serum albumin (Table 2).

Backward stepwise logistic regression model was conducted to explore predictors of positive $H$. pylori infection (Table 3). In the last step, only eating from street vendors $(\mathrm{OR}=1.879,95 \% \mathrm{CI} 1.346-2.625 ; P<0.001)$, absence of pure water supply $(\mathrm{OR}=1.725,95 \% \mathrm{CI}$ $1.162-2.561 ; P=0.007)$, and overcrowding $(\mathrm{OR}=1.547$, 95\% CI $1.100-2.177 ; P=0.012)$ remained the significant predictors of $H$. pylori infection.

\section{Discussion}

To the authors' best knowledge, this is the first study conducted in the Pediatric Hospital at Cairo University to detect the prevalence and predictors of $H$. pylori infection among children, and the effect of infection on children's growth parameters. The current study showed a high prevalence (64.6\%) of $\mathrm{H}$. pylori infection among symptomatic children attending the Outpatient Clinics of the Gastroenterology unit. This result is lower than that observed in previous studies among children in Egypt, which reported $H$. pylori infection in $72.4 \%$ and $68 \%$ of children $[21,24]$. However, it is higher than that detected in other countries of the Eastern Mediterranean region like Saudi Arabia, where a 49.8\% prevalence of $H$. pylori infection was detected among symptomatic children [25]. This variation of infection rates between studies is probably due to differences in the study design, patient inclusion criteria, sample size, and techniques used for $H$. pylori detection.

In this study, the prevalence of $H$. pylori was found to increase with age; children $>10$ years had the highest $H$. pylori infection rates $(32.9 \%)$, while those $<3$ years had the lowest (13.8\%). Similarly in a study conducted by Hasosah et al. [25], the prevalence of $H$. pylori was $10.5 \%$ among children $<3$ years old; however, it reached $57.7 \%$ among those $>10$ years old. This could be explained by increased children's contact with the community and outdoor exposure with practicing faulty dietary practices like eating from street vendors. In contrast, other studies found that infection increases in early childhood due to bed or bedroom sharing with an infected sibling $[7,26]$. In accordance with other studies $[25$, 27], gender was not found to be a risk factor for childhood infection with $H$. pylori in the present study.

Children from rural areas had a significantly higher infection rates than those from urban areas $(60.4 \%$ vs. $39.6 \%, P<0.004)$. Consistent with the findings of the present study, Sayed et al. reported a higher seroprevalence of H. pylori infection in rural areas in Assiut Governorate than in urban areas [18]. This could be attributed to the poor socio-economic status, poor sanitation, bad hygienic behaviors, and absence of sources of pure water supply among people living in rural areas.

Educational level has been known as an important determinant of $H$. pylori prevalence in both developed and developing countries [28]. In the current study, illiteracy of mothers was significantly associated with positive $H$. pylori infection; this could be explained by the assumption that the mothers' educational status reflects on the healthy habits and hygienic behavior acquired by their children. This goes in accordance with a study conducted by Malaty et al., where children whose mothers did not complete high school had higher rates of $H$. pylori infection compared to those whose mothers had a partial or complete college education [29]. However, 
Table 2 Comparison between $\mathrm{H}$. pylori-infected and non-infected symptomatic children regarding anthropometric measurements and laboratory investigations

\begin{tabular}{|c|c|c|c|c|c|}
\hline & Stool an & ylori among ma & & & \\
\hline & $+\operatorname{VE}(n=$ & & $-\mathrm{VE}(n=$ & & $p$ value $\mathrm{e}^{@}$ \\
\hline & Median & IQR & Median & IQR & \\
\hline Males & & & & & \\
\hline WAZ & -1.1 & -2.5 to -0.4 & -1.0 & -2.2 to -0.3 & 0.052 \\
\hline $\mathrm{HAZ}$ & -1.6 & -2.3 to -0.7 & -1.4 & -2.2 to 0.0 & 0.219 \\
\hline WHZ & -1.2 & -2.3 to 0.5 & -0.2 & -1.7 to 0.5 & 0.103 \\
\hline Hemoglobin $[\mathrm{gm} / \mathrm{dl}]$ & 10.5 & $9.4-11.4$ & 11.0 & $9.8-13.0$ & $<0.001$ \\
\hline Ferritin [ng/dl] & 15.1 & $9.0-29.5$ & 41.0 & $16.0-60.0$ & $<0.001$ \\
\hline Serum iron [ug/dl] & 42.0 & $27.0-70.0$ & 41.0 & $32.0-54.0$ & 0.832 \\
\hline INR & 1.1 & $1.0-1.2$ & 1.0 & $1.0-1.1$ & 0.152 \\
\hline ALT & 33.0 & $28.0-59.0$ & 33.0 & $26.5-49.0$ & 0.935 \\
\hline AST & 45.0 & $41.0-68.0$ & 44.0 & $39.0-82.0$ & 0.862 \\
\hline Serum albumin & 3.8 & $3.4-4.3$ & 3.9 & $3.7-4.4$ & 0.043 \\
\hline Females & & & & & \\
\hline WAZ & -1.4 & -2.8 to -0.2 & -0.5 & -2.1 to 0.1 & 0.003 \\
\hline HAZ & -0.9 & -2.0 to 0.4 & -0.4 & -1.2 to 0.2 & 0.097 \\
\hline WHZ & -1.5 & -3.6 to -0.5 & -0.3 & -2.6 to 0.2 & 0.006 \\
\hline Hemoglobin $[\mathrm{gm} / \mathrm{dl}]$ & 10.6 & $9.5-11.1$ & 11.2 & $10.5-13.0$ & $<0.001$ \\
\hline Ferritin [ng/dl] & 25.3 & $8.6-60.0$ & 38.0 & $15.1-78.0$ & 0.027 \\
\hline Serum iron [ug/dl] & 37.9 & $25.0-74.0$ & 46.0 & $39.0-80.0$ & 0.002 \\
\hline INR & 1.0 & $1.0-1.1$ & 1.1 & $1.0-1.2$ & 0.010 \\
\hline ALT & 31.0 & $27.0-49.0$ & 28.0 & $25.0-49.0$ & 0.045 \\
\hline AST & 45.0 & $35.0-73.0$ & 38.0 & $32.0-82.0$ & 0.033 \\
\hline Serum albumin & 4.1 & $3.6-4.3$ & 3.9 & $3.6-4.1$ & 0.096 \\
\hline The whole sample & & & & & \\
\hline WAZ & -1.3 & -2.7 to -0.4 & -0.7 & -2.1 to -0.1 & $<0.001$ \\
\hline HAZ & -1.3 & -2.2 to 0.1 & -0.9 & -2.0 to 0.1 & 0.036 \\
\hline WHZ & -1.2 & -2.9 to 0.3 & -0.3 & -2.1 to 0.5 & 0.005 \\
\hline Hemoglobin [gm/dl] & 10.6 & $9.4-11.2$ & 11.0 & $10.1-13.0$ & $<0.001$ \\
\hline Ferritin [ng/dl] & 17.5 & $9.0-60.0$ & 41.0 & $15.1-60.0$ & $<0.001$ \\
\hline Serum iron [ug/dl] & 41.0 & $25.0-71.0$ & 46.0 & $34.0-70.0$ & 0.015 \\
\hline INR & 1.0 & $1.0-1.1$ & 1.0 & $1.0-1.2$ & 0.453 \\
\hline ALT & 31.0 & $27.0-59.0$ & 31.0 & $25.0-49.0$ & 0.191 \\
\hline AST & 45.0 & $36.0-68.0$ & 44.0 & $34.0-82.0$ & 0.242 \\
\hline Serum albumin & 3.9 & $3.5-4.3$ & 3.9 & $3.6-4.4$ & 0.585 \\
\hline
\end{tabular}

IQR interquartile range, $W A Z$ weight-for-age $Z$ score, $H A Z$ height-for-age $Z$ score, $W H Z$ weight-for-height $Z$ score, INR international normalized ratio, $A L T$ alanine transaminase, AST aspartate Aminotransferase

${ }^{@}$ Mann Whitney test

Awuku et al. found no significant association between the educational level of either parents and the prevalence of H. pylori infection [6].

Overcrowded conditions especially in developing countries have been reported as a major risk factor for H. pylori infection, because that creates closer contact between mothers and children and between siblings that might spread the infection to each other [30]. In this study, household crowding index $\geq 3$ was significantly associated with positive $H$. pylori infection $(P=0.011)$.

Another important environmental risk factor that has been linked to $H$. pylori spread in previous studies is the absence of a source of pure water supply [6,31]. Similarly, 


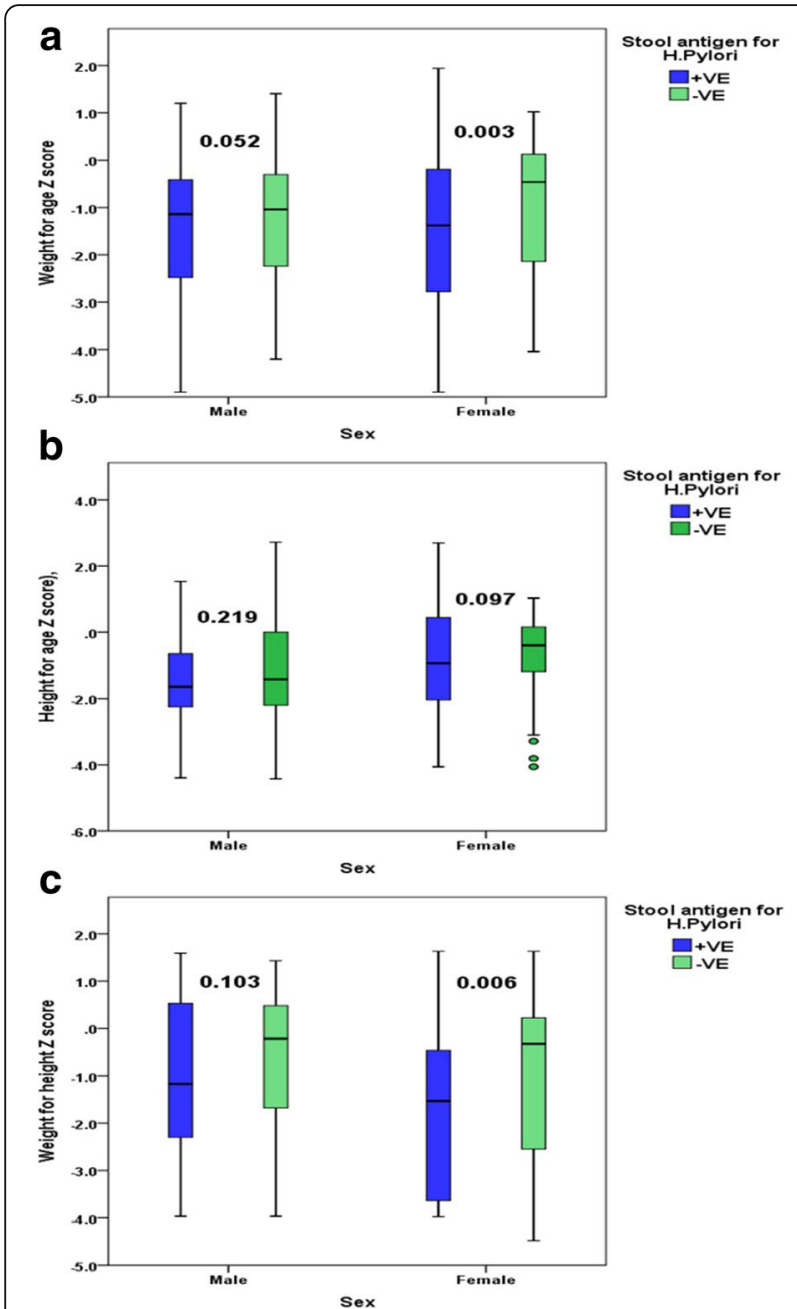

Fig. 1 a Box plot showing distribution of WAZ in relation to sex and $H$. pylori infection. $\mathbf{b}$ Box plot showing distribution of HAZ in relation to sex and $H$. pylori infection. $\mathbf{c}$ Box plot showing distribution of $\mathrm{WHZ}$ in relation to sex and $H$. pylori infection

our study found that a significantly higher percent of non-infected children had a source of pure water supply compared to infected children $(79.8 \%$ vs. $69.5 \%, P=0.005)$. Moreover, the role of food-borne transmission of $H$. pylori has been stated in the literature [32], especially in developing countries where bad sanitary conditions exist such as the presence of flies, bad hygiene, and eating fruits and vegetables without washing them or eating uncooked vegetables. In agreement with that, the present study detected a significant association between eating from street vendors where sanitary measures are not guaranteed and positive $H$. pylori infection $(P<0.001)$.

In this study, abdominal pain, vomiting, hematemesis, and pallor were among the significant clinical predictors of H. pylori infection. Similarly, in a study conducted in Saudi Arabia, children with abdominal pain were 2.39 times more likely to have $H$. pylori infection [25].

There is noticeable controversy in the findings of studies examining the effect of $H$. pylori infection on growth in children, as some illustrated the presence $[13,33]$ of association and others denied it $[34,35]$. However, new evidence has emerged recently from the studies of Mera et al. [36] and Yang et al. [37] who reported a beneficial effect of $H$. pylori eradication on the growth of children. In the current study, the values of WAZ, WHZ, and HAZ were significantly reduced in infected children compared to non-infected ones. However, distribution of these measurements according to infection status and sex revealed significant reduction in WAZ and WHZ values in infected females compared to non-infected ones; non-affection of the HAZ could be explained by early detection of $H$. pylori infection before affecting the chronic malnutrition index (HAZ). However, there were no significant differences in values of WAZ, WHZ, and HAZ between infected and non-infected males, which may be explained by gender discrimination and deeply rooted traditions and beliefs where more attention is given to male infants especially in a developing country like Egypt. Similarly, in a study conducted in Egypt to examine the effect of $H$. pylori infection on children growth [21], the prevalence of stunted growth was higher in infected children than in children free of infection; also the values of WAZ and weight-for-age percentile score (WAP) signified reduced growth in children with $H$. pylori compared with children free of infection; however, in that study, the differences in height and weight associated with $H$. pylori infection were more noticeable in boys than girls.

Regarding the association between $H$. pylori infection and other extra-digestive parameters in the current study, significant reduction was observed in the levels of serum hemoglobin, iron, and ferritin among infected children compared to non-infected ones. Similarly, several studies

Table 3 Backward stepwise logistic regression model for predictors of H. pylori infection among symptomatic Egyptian children

\begin{tabular}{lllll}
\hline & $\beta$ & $p$ value & Adjusted OR & $95 \% \mathrm{Cl}$ \\
\hline Eating from street vendors & 0.631 & $<0.001$ & 1.879 & $1.346-2.625$ \\
Absence of pure water supply & 0.545 & 0.007 & 1.725 & $1.162-2.561$ \\
Overcrowding & 0.436 & 0.012 & 1.547 & $1.100-2.177$ \\
Constant & -0.134 & 0.424 & 0.875 & - \\
\hline
\end{tabular}

$\beta$ beta coefficient, $O R$ odds ratio, $\mathrm{Cl}$ confidence interval) 
conducted in both developed and developing countries revealed lower serum ferritin and hemoglobin concentrations [38], and/or higher proportion of iron deficiency (ID) or IDA $[39,40]$ in $H$. pylori positive than in $H$. pylori-negative children. In contrast, other studies failed to prove such association [41].

In this study, variables that were significantly associated with $H$. pylori infection and were retained in logistic regression model and thus could be considered as potential predictors for $H$. pylori infection included eating from street vendors, absence of pure water supply, and overcrowding. In another study conducted by Hasosah et al. [25], variables that remained significant for $H$. pylori infection in the multivariate model were age $>10$ years, bed sharing, contact with the community, a high number of family members, and low income.

\subsection{Limitations of the study}

Among the limitations of this study was the involvement of symptomatic children admitted to the Outpatient Clinics of the Gastroenterology Unit at the Pediatric Hospital, Cairo University, for diagnosis and treatment and not the general population. Also, the socioeconomic and behavioral risk factors were reported by the children's parents and thus may not be so accurate.

\section{Conclusion}

This study revealed a high prevalence of $H$. pylori infection (64.6\%) among symptomatic children attending the Outpatient Clinics of the Pediatric Hospital, Cairo University. Residence in rural areas, educational status of mothers (non-educated), household crowding index $\geq 3$, absence of pure water supply, and eating from street vendors were significantly associated with $H$. pylori infection. After conducting a stepwise logistic regression analysis, only eating from street vendors, absence of pure water supply, and overcrowding remained the significant predictors of infection. Also, the extra-digestive effects of $H$. pylori were demonstrated; the values of growth parameters (WAZ, HAZ, and WHZ) and levels of serum hemoglobin, iron, and ferritin were significantly lower in infected children. Based on the findings of this study, it is recommended that diagnostic and treatment programs for $H$. pylori be considered a public health priority especially in a developing country like Egypt. Further studies among asymptomatic children are also needed to tackle this problem.

\section{Abbreviations}

ALT: Alanine transaminase; AST: Aspartate transaminase; CDC: Centers of Disease Control and Prevention; Cl: Confidence interval; H. pylori: Helicobacter pylori; HAZ: Height-for-age; ID: Iron deficiency; IDA: Iron-deficiency anemia; INR: International normalized ratio; IQR: Interquartile range; NA: Not applicable; OR: Odds ratio; PC: Prothrombin concentration; PT: Prothrombin time; SPSS: Statistical Package of Social Science; WAP: Weight-for-age percentile; WAZ: Weight-for-age; WHZ: Weight-for-height; $\beta$ : Beta coefficient

\section{Acknowledgements}

The authors are thankful to the Chairmen of the Pediatric and Clinical Pathology Departments at Cairo University Hospitals for conducting this study. The authors also thank all the nursing staff in the Gastroenterology Unit at the Pediatric Hospital who helped the researchers during the data collection. The research team also thanks the patients' parents and relatives.

\section{Funding}

This research did not receive any specific grant from funding agencies in the public, commercial, or not-for-profit sectors.

\section{Availability of data and materials}

The datasets used and/or analyzed during the current study are available from the corresponding author on reasonable request.

\section{Authors' contributions}

YG carried out the initial analyses and statistical analysis, critically reviewed the manuscript, and prepared the paper for submission. CG designed the data collection forms, coordinated and supervised data collection, and revised the manuscript. $J$ conceptualized and designed the study and drafted the initial manuscript. MA helped to draft and revise the manuscript. All authors read and approved the final manuscript.

\section{Ethics approval and consent to participate}

Approval of the study protocol was obtained from the Ethical Committee at the Public Health and Community Medicine Department at the Faculty of Medicine, Cairo University. However, the Committee does not provide us with a reference number for approval. Required permissions for conducting the study were obtained from the Chairman of the Pediatric Hospital and from the head of the Gastroenterology Unit. A verbal informed consent was obtained directly from the legal guardian of all participants before data collection and after explanation of the study objectives. The Ethical Committee approved verbal consents because this study was conducted in a tertiary hospital draining from poor socioeconomic levels and it was expected that a considerable percent of the mothers was not educated. All procedures for data collection were treated with confidentiality.

Consent for publication

Not applicable.

\section{Competing interests}

The authors declare that they have no competing interests.

\section{Publisher's Note}

Springer Nature remains neutral with regard to jurisdictional claims in published maps and institutional affiliations.

\section{Author details}

${ }^{1}$ Departments of Public Health and Community Medicine, Faculty of Medicine, Cairo University, 31 Mohamed Hassan El-Gamal Street, Nasr City, Cairo 11759, Egypt. 'Pediatrics, Faculty of Medicine, Cairo University, 115 El Manial Street, Cairo 11451, Egypt. ${ }^{3}$ Pediatrics, Faculty of Medicine, , Cairo University, 7 Riyad Abdel Kader, Nasr City, Cairo 11759, Egypt. ${ }^{4}$ Pediatrics, Faculty of Medicine, , Cairo University, 47 El-Sudan Street, Dokki, Giza 13211, Egypt.

Received: 1 November 2018 Accepted: 17 April 2019

Published online: 24 May 2019

\section{References}

1. Go MF. Review article: natural history and epidemiology of Helicobacter pylori infection. Aliment Pharmacol Ther. 2002;16 (Suppl. 1:3-15.

2. Malaty HM, El-Kasabany A, Graham DY, Miller CC, Reddy SG, Srinivasan SR, et al. Age at acquisition of Helicobacter pylori infection: a follow-up study from infancy to adulthood. Lancet. 2002;359:931-5.

3. Queiroz DM, Rocha AM, Crabtree JE. Unintended consequences of Helicobacter pylori infection in children in developing countries: iron deficiency, diarrhea, and growth retardation. Gut Microbes. 2013;4:494-504.

4. Feldman RA. Epidemiologic observations and open questions about disease and infection caused by Helicobacter pylori. In: Achtman M, Suerbaum S, editors. 
Helicobacter pylori: molecular and cellular biology. Wymondham: Horizon scientific press; 2001. p. 29-51.

5. Bardhan PK. Epidemiological features of helicobacter pylori infection in developing countries. Clin Infect Dis. 1997;25:973-8.

6. Awuku YA, Simpong DL, Alhassan IK, Tuoyire DA, Afaa T, Adu P. Prevalence of Helicobacter pylori infection among children living in a rural setting in subSaharan Africa. BMC Public Health. 2017;17:360.

7. Salih BA. Helicobacter pylori infection in developing countries: the burden for how long? Saudi J Gastroenterol. 2009;15:201-7.

8. Cheng H, Hu F, Zhang L, Yang G, Ma J, Hu J, et al. Prevalence of Helicobacter pylori infection and identification of risk factors in rural and urban Beijing, China. Helicobacter. 2009;14:128-33.

9. Bellack NR, Koehoorn MW, MacNab YC, Morshed MG. A conceptual model of water's role as a reservoir in Helicobacter pylori transmission: a review of the evidence. Epidemiol Infect. 2006;134:439-49.

10. Bittencourt PF, Rocha GA, Penna FJ, Queiroz DM. Gastroduodenal peptic ulcer and Helicobacter pylori infection in children and adolescents. J Pediatr. 2006;82(5):325-34.

11. Potamitis GS, Axon AT. Helicobacter pylori and nonmalignant diseases. Helicobacter. 2015;20(1):26-9.

12. Thomas JE, Dale A, Bunn JE, Harding M, Coward WA, Cole TJ, et al. Early Helicobacter pylori colonisation: the association with growth faltering in the Gambia. Arch Dis Child. 2004:89:1149-54.

13. Fialho AM, Braga AB, Queiroz DM, Rodrigues MN, Herbster ID, Braga LL. The association between Helicobacter pylori infection and height in children from an urban community in north-east Brazil. Ann Trop Paediatr. 2007;27:55-61.

14. Goodman KJ, Correa P, Mera R, Yepez MC, Cerón C, Campo C, et al. Effect of Helicobacter pylori infection on growth-velocity of school-age Andean children. Epidemiology. 2011;22:118-26.

15. Franceschi F, Annalisa T, Teresa DR, Giovanna D, laniro G, Franco S, et al. Role of Helicobacter pylori infection on nutrition and metabolism. World J Gastroenterol. 2014;20:12809-17.

16. Annibale B, Capurso G, Delle Fave G. Consequences of Helicobacter pylori infection on the absorption of micronutrients. Dig Liver Dis. 2002;34:72-7.

17. Taye B, Enquselassie F, Tsegaye A, Amberbir A, Medhin G, Fogarty A, et al. Effect of Helicobacter pylori infection on growth trajectories in young Ethiopian children: a longitudinal study. Int J Infect Dis. 2016;50:57-66.

18. Sayed ASM, Abd Al-Azeem MW, Noaman HA, Hassan MA. Seroepidemiological study on Helicobacter pylori infection in children and adults in Assiut Governorate, Upper Egypt. J Arab Soc Med Res. 2007;2(2):129-33.

19. Diab M, El-Dine SS, Aboul-Fadl L, Shemis M, Omran Z, Badawi A, et al. Helicobacter pylori cag pathogenicity island genes among dyspeptic patients with chronic gastritis. Egypt J Med Microbiol. 2009;18:43-53.

20. Naficy AB, Frenck RW, Abu-Elyazeed R, Kim Y, Rao MR, Savarino SJ, et al. Seroepidemiology of Helicobacter pylori infection in a population of Egyptian children. Int J Epidemiol. 2000;29:928-32.

21. Mohammad MA, Hussein L, Coward A, Jackson SJ. Prevalence of Helicobacter pylori infection among Egyptian children: impact of social background and effect on growth. Public Health Nutr. 2008;11:230-6.

22. CDC online calculators. https://www.cdc.gov/healthyweight/bmi/calculator. html. Accessed 15 Apr 2017.

23. Kazemi S, Tavakkoli H, Habizadeh MR, Emami MH. Diagnostic values of Helicobacter pylori diagnostic tests: stool antigen test, urea breath test, rapid urease test, serology and histology. J Res Med Sci. 2011;16(9):1097-104.

24. Abdulqawi K, El-Mahalaway AM, Abdelhameed A, Abdelwahab AA. Correlation of serum antibody titres with invasive methods for rapid detection of Helicobacter pylori infections in symptomatic children. Int J Exp Patholo. 2012;93:295-304.

25. Hasosah M, Satti M, Shehzad A, Alsahafi A, Sukkar G, Alzaben A, et al. Prevalence and risk factors of Helicobacter pylori infection in Saudi children: a three-year prospective controlled study. Helicobacter. 2015;20:56-63.

26. Farrel S, Doherty G, Milliken I, Shield MD, McCallion WA. Risk factors for Helicobacter pylori infection in children. An examination of the role played by intrafamilial bed sharing. Pediatr Infect Dis. 2005;24:149-52.

27. Nabwera HM, Nguyen-Van-Tam JS, Logan RF, Logan RP. Prevalence of Helicobacter pylori infection in Kenyan schoolchildren aged 3-15 years and risk factors for infection. Eur J Gastroenterol Hepatol. 2000;12:483-7.

28. Darko R, Yawson AE, Osei V, Owusu-Ansah J, Aluze-Ele S. Changing patterns of the prevalence of Helicobacter pylori among patients at a corporate hospital in Ghana. Ghana Med J. 2015;49(3):147-53.

29. Malaty HM, Logan ND, Graham DY, Ramchatesingh JE. Helicobacter pylori infection in preschool and school-aged minority children: effect of socioeconomic indicators and breast-feeding practices. Clin Infect Dis. 2001; 32(10):1387-92

30. Goodman KJ, Correa P. Transmission of Helicobacter pylori among siblings. Lancet. 2000;355:358-62.

31. Aziz RK, Khalifa MM, Sharaf RR. Contaminated water as a source of Helicobacter pylori infection. A review. J Adv Res. 2015;6(4):539-47.

32. Hopkins RJ, Vial PA, Ferreccio C, Ovalle J, Prado P, Sotomayor V, et al. Seroprevalence of Helicobacter pylori in Chile: vegetables may serve as one route of transmission. J Infect Dis. 1999;168:222-6.

33. Vilchis J, Duque X, Mera R, Morán S, Torres J, González-Cossío T, et al. Association of Helicobacter pylori infection and height of Mexican children of low socioeconomic level attending boarding schools. Am J Trop Med Hyg. 2009;81:1091-6.

34. Ozçay F, Demir H, Özen H, Gürakan F, Saltik IN, Yüce A, et al. Normal growth in young children with Helicobacter pylori infection. J Pediatr Gastroenterol Nutr. 2002;35:102

35. Chimonas MAR, Baggett HC, Parkinson AJ, Muth PT, Dunaway E, Gessner BD. Asymptomatic Helicobacter pylori infection and iron deficiency are not associated with decreased growth among Alaska Native children aged 7-11 years. Helicobacter. 2006;11:159-67.

36. Mera RM, Bravo LE, Goodman KJ, Yepez MC, Correa P. Long- term effects of clearing Helicobacter pylori on growth in school-age children. Pediatr Infect Dis J. 2012;31:263-6.

37. Yang YJ, Sheu BS, Yang HB, Lu CC, Chuang CC. Eradication of Helicobacter pylori increases childhood growth and serum acylated ghrelin levels. World J Gastroenterol. 2012:18:2674-81.

38. Queiroz DMM, Harris PR, Sanderson IR, Windle HJ, Walker MM, Rocha AMC, et al. Iron status and Helicobacter pylori infection in symptomatic children: an international multi-centered study. PLoS One 2013; 8:e68833.

39. Muhsen K, Barak M, Henig C, Alpert G, Ornoy A, Cohen D. Is the association between Helicobacter pylori infection and anemia age dependent? Helicobacter. 2010;15:467-72.

40. Afifi RA, Ali DK, Shaheen IA. A localized case control study of extra-gastric manifestations of Helicobacter pylori infection in children. Indian J Pediatr. 2011:78:418-22

41. Vendt N, Kool P, Teesalu K, Lillemäe K, Maaroos HI, Oona M. Iron deficiency and Helicobacter pylori infection in children. Acta Paediatr. 2011;100:1239-43.

\section{Submit your manuscript to a SpringerOpen ${ }^{\circ}$ journal and benefit from:}

- Convenient online submission

- Rigorous peer review

- Open access: articles freely available online

High visibility within the field

- Retaining the copyright to your article

Submit your next manuscript at $>$ springeropen.com 